\title{
Acceptance of psoriasis in the context of body image, body experience, and social support
}

\begin{abstract}
BACKGROUND
Acceptance of disease is an important determinant of quality of life in psoriasis patients. Social support and positive body image are considered important contributors to coping with the disease, but no studies have yet examined the role of body image and body experience in relation to psychological adjustment to psoriasis. We aimed to identify the role of biopsychosocial aspects - medical characteristics, body image, body experience, and social support - in acceptance of psoriasis.
\end{abstract}

\section{PARTICIPANTS AND PROCEDURE}

The Berlin Social Support Scale, the Acceptance of Illness Scale, and the Body-Self Questionnaire (BSQ) were administered to 109 patients. Disease severity was measured with the Psoriasis Area and Severity Index (PASI).

\section{RESULTS}

None of the investigated medical aspects were related to disease acceptance. Disease acceptance was associated with perceived social support (instrumental, informational, and emotional) and the following aspects of body experience and body image: lack of disturbances in perceiving, interpretation and regulation of emotions and physiological needs, appearance satisfaction, acceptance of biological sex, and fitness satisfaction. The acceptance of appearance and biological sex and social support were the best predictors, explaining $33 \%$ of the variance in disease acceptance $\left(R^{2}=.33, F=18.93\right)$.

\section{CONCLUSIONS}

Disease acceptance is independent of medical disease parameters, which demonstrates the limitations of the biomedical model in explaining the process of coping with psoriasis. Our findings demonstrate the buffering effect of social support, positive body image, and body experience against the negative consequences of psoriasis. Psychological intervention focused on body image and body experience enhancement can support psychological adjustment to disease.

\section{KEY WORDS}

psoriasis; adaptation to disease; body image; social support; body experience

Organization - 1: Department of Psychology, Adam Mickiewicz University, Poznan, Poland · 2: Department of Geriatric Medicine and Gerontology, Poznan University of Medical Sciences, Poznan, Poland · 3: Department of Dermatology, Poznan University of Medical Sciences, Poznan, Poland

aUthors' Contributions - A: Study design - B: Data collection - C: Statistical analysis · D: Data interpretation .

E: Manuscript preparation · F: Literature search · G: Funds collection

Corresponding author - Olga Sakson-Obada, Ph.D., Institute of Psychology, 89 Szamarzewskiego Str., 60-568 Poznan, Poland, e-mail: osakson@wp.pl

to Cite this ARTICle - Sakson-Obada, O., Pawlaczyk, M., Gerke, K., \& Adamski, Z. (2017). Acceptance of psoriasis in the context of body image, body experience, and social support. Health Psychology Report, 5(3), 251-257. doi: https://doi. org $/ 10.5114 /$ hpr.2017.63824

RECEIVED 03.07.2016 · REVIEWED 31.07.2016 · ACCEPTED 09.09.2016 · PUBLISHED 01.02.2017 


\section{BACKGROUND}

Psoriasis is a chronic, immune-mediated skin disorder affecting approximately $2 \%$ of the Caucasian population (Kurd \& Gelfand, 2009). It appears as symmetrical, sharply demarcated erythematous scaling plaques, involving the skin in typical areas, including in sites visible to others. The disease may cause low self-esteem or adversely influence social and emotional life (Richards, Fortune, Griffith, \& Main, 2001). Psoriasis
Olga Sakson-Obada, Mariola Pawlaczyk, Katarzyna Gerke, Zygmunt Adamski patients suffer from chronic stress, depression, anxiety, sexual problems, social stigmatization, and negative body image (Hayes \& Ko, 2010; Molina-Leyva, Jiménez-Moleón, Naranjo-Sintes, \& Ruiz-Carrascosa, 2015; Vardy, Besser, Amir, Biton, \& Buskila, 2002; Khoury, Danielsen, \& Skiveren, 2012). According to Gupta and Gupta (1995), daily exposure to chronic, low-intensity stress, resulting from negative image of one's body and the feeling of social rejection, has a greater influence on the course of psoriasis than acute single-event stress. Stress due to coping with the disease on a daily basis constitutes a prognostic factor of disturbances within the psychosocial domain in psoriasis patients (Gupta, Gupta, \& Haberman, 1987).

Leventhal et al. (1997), introduced a model linking illness representation with stress. Illness representation (e.g. belief of cause, consequences, control, duration) guides perception, memory and coping behaviour, and shapes the outcome in terms of distress or positive mobilization. Disease acceptance understood as adjustment to an illness, not in terms of resignation or withdrawal but realistic appraisal of its course, is believed to be the best determinant of quality of life in patients with chronic psoriasis (Zalewska, Miniszewska, Chodkiewicz, \& Narbutt, 2007). It was proved that adaptation to psoriasis is a complex process, engaging internal psychological factors (e.g. strategies of affect regulation) and various aspects of personality (e.g. optimism, locus of control), as well as external factors (e.g. social support) (Zalewska et al., 2007; Basińska \& Kasprzak, 2012; Janowski et al., 2012; Adamska \& Miniszewska, 2016).

As disease acceptance is important for patient well-being, we decided to examine two variables which may influence adjustment to psoriasis: psychological (body image and body experience) and social (perceived social support). Although it was emphasized that body image is strongly affected by psoriasis (Vardy et al., 2002; Leichtman, Burnett, \& Robinson, 1981), to the best of our knowledge, no study has analyzed the impact of body image or body experience on the acceptance of psoriasis. We used the model of body self developed by Sakson-Obada (2009; Sakson-Obada \& Wycisk, 2015), which is a complex structure of personality, composed of body image and body experience. In this model, body image relates to beliefs and feelings about the body.
It covers different body characteristics, for example appearance, fitness, and biological sex. On the other hand, body experience is related to the psychological functions, which enable individuals to feel changes occurring in the body (perception), to make these changes meaningful (interpretation in terms of emotions and physiological needs), and to specify their causes and ways of coping with them (regulation). It was proved that ability to feel, understand, and cope with sensations, emotions and physiological needs plays an important role in dealing with stress and promoting self-care behaviour (Sakson-Obada, 2009; Kubiak \& Sakson-Obada, 2016), whereas negative body image contributes to various psychological disorders, such as eating disorders (Cash \& Deagle, 1997), self-injury behaviour (Kubiak \& Sakson-Obada, 2016), and depression (Teo, Novy, Chang, Cox, \& Fingeret, 2015; Blashill \& Wilhelm, 2014).

The aim of the study was to examine the relationship between disease acceptance and selected medical and psycho-social aspects. We assumed that demographic and medical variables would be relatively irrelevant to disease acceptance, and patients with a more positive body image, less distorted body experience, and higher level of social support would exhibit a higher level of disease acceptance.

\section{PARTICIPANTS AND PROCEDURE}

A total of 109 patients with plaque psoriasis, without any concomitant diseases and medications, treated at the Department of Dermatology, Poznan University of Medical Sciences and the Dermatology out-patient clinic of the Hospital of the Ministry of Interior in Poznan, between November 2015 and February 2016, due to exacerbation of psoriasis, were recruited. The study group included 54 men and 55 women, aged from 18 to 89 years, mean 46.35, SD 13.81. All patients underwent clinical examination. Disease severity was measured with PASI (Schmitt \& Wozel, 2005). The Local Ethics Committee approved of the study (No. 1048/15). Written informed consent was obtained from all subjects. All patients completed the Polish version of the following questionnaires: the Berlin Social Support Scale (BSSS), the Acceptance of Illness Scale (AIS), and the Body Self Questionnaire (BSQ).

The BSSS is a self-report instrument used to assess various aspects of social support (Schulz \& Schwarzer, 2003; Polish adaptation: Łuszczyńska, Kowalska, Mazurkiewicz, \& Schwarzer, 2006). Two scales were selected for the purpose of this study: Perceived available support and Actually received support. Both scales are divided into sub-scales which measure emotional and instrumental types of support. Moreover, the Actually received support scale includes an informational subscale and one question about satisfaction with support. The responses are 
given using a 4-point Likert scale, from strongly disagree to strongly agree. Higher scores correspond to a higher level of social support.

The AIS is used to measure the degree of disease acceptance, understood as the ability to adapt and/ or overcome the limitations imposed by the illness (Felton, Revenson, \& Hinrichsen, 1984; Polish adaptation: Juczyński, 2009). It is composed of 8 statements about negative consequences of the disease, such as activity limitation, lower self-esteem, and negative attitudes of others. Answers are given on a 5-point Likert scale, from strongly disagree to strongly agree. Higher scores correspond to a higher degree of disease acceptance.

The BSQ is composed of 68 and 71 statements in the version for women and men, respectively (Sakson-Obada, 2009). It includes body experience and body image scales. There are four sub-scales which measure disturbances in body experience: (1) Lowered threshold; (2) Heightened threshold (both sub-scales measure disturbances of perception); (3) Interpretation of emotion and physiological needs; (4) Regulation of emotion and physiological needs. Three scales measure body image satisfaction: (5) Appearance satisfaction; (6) Fitness satisfaction; (7) Acceptance of biological sex. Higher scores reflect a greater number of disturbances in body image and body experience. Answers can be given on a 5-point Likert scale $(1$ - not true at all, 5 - very true). The questionnaire was proved to differentiate the normal population and clinical groups in which disturbances in body image and body experience were assumed (Kubiak \& Sakson-Obada, 2016; Sakson-Obada \& Wycisk, 2015).

Statistical analyses were performed using IBM SPSS Statistics (version 23). We used Spearman coef- ficients to examine the relations between BSQ, PASI, age, disease duration, age at onset, and AIS. To compare AIS among males and females, patients of different economic status, education level, and relationship status, Student's $t$-test test or Fisher's test (one-way ANOVA) was used. Furthermore, multiple linear regression was performed by the step method to identify the predictors of psoriasis acceptance. $P$-values of $<.05$ were considered statistically significant.

\section{RESULTS}

Mean patient age was 46.35 years, $S D=13.81$ (range 18-89). Mean PASI score was $11.06, S D=4.59$ (range 2-21), mean disease duration was 19.53 years, $S D=13.37$ (range 1-61), and age at onset was 26.65 years, $S D=11.99$ (range 1-63). Table 1 shows the results of the evaluation of disease acceptance in relation to demographic variables. Sex, relationship status, education and age $(\rho=.02, p=.871)$ were not related to disease acceptance. Patients in a good financial situation accepted psoriasis more, as compared to individuals with lower economic status.

None of the analyzed medical aspects was related to disease acceptance. Disease acceptance was not related to PASI $(\rho=-.06, p=.573)$, age at onset $(\rho=-.09$, $p=.313)$, or disease duration $(\rho=.02, p=.871)$. The level of psoriasis acceptance in patients with persistent lesions did not differ from individuals with disease-free periods $(t=-0.42, p=.680)$.

The correlation analysis was applied to test whether social support, body image and body experience are associated with the acceptance of psoriasis. The results are presented in Table 2. All aspects of social support received from one person (instrumen-
Acceptance of psoriasis, body image and social support

Table 1

Psoriasis acceptance in relation to demographic variables

\begin{tabular}{|c|c|c|c|c|c|}
\hline \multirow[t]{2}{*}{ Variable } & \multirow[t]{2}{*}{ Group $(n, \%)$} & \multicolumn{4}{|c|}{ Disease acceptance } \\
\hline & & $M$ & $S D$ & Test $(T / F)$ & $p$ \\
\hline Sex & $\begin{array}{c}\text { Male }(n=54,49.54 \%) \\
\text { Female }(n=55,50.46 \%)\end{array}$ & $\begin{array}{l}3.61 \\
3.78\end{array}$ & $\begin{array}{l}1.03 \\
0.93\end{array}$ & $-0.90(T)$ & .372 \\
\hline Relationship status & $\begin{array}{c}\text { Single }(n=27,24.77 \%) \\
\text { Partnership }(n=82,75.23 \%)\end{array}$ & $\begin{array}{l}3.59 \\
3.75\end{array}$ & $\begin{array}{l}1.09 \\
0.94\end{array}$ & $-0.69(T)$ & .502 \\
\hline Economic status & $\begin{array}{c}\text { Good }(n=50,45.91 \%) \\
\text { Medium }(n=51,46.82 \%) \\
\text { Low }(n=8,7.32 \%)\end{array}$ & $\begin{array}{l}4.00 \\
3.48 \\
3.17\end{array}$ & $\begin{array}{l}0.85 \\
1.02 \\
1.01\end{array}$ & $5.25(F)$ & .074 \\
\hline Education & $\begin{array}{c}\text { Primary education }(n=3,2.74 \%) \\
\text { Vocational education }(n=12,11.00 \%) \\
\text { Secondary education }(n=43,39.44 \%) \\
\text { Incomplete higher education }(n=12,11.00 \%) \\
\text { Higher education }(n=29,58.00 \%)\end{array}$ & $\begin{array}{l}3.31 \\
2.94 \\
3.80 \\
3.92 \\
3.74\end{array}$ & $\begin{array}{l}0.44 \\
1.06 \\
0.95 \\
0.95 \\
0.95\end{array}$ & $2.12(F)$ & .691 \\
\hline
\end{tabular}

Note. $T$ - Student's $t$-test, $F$ - Fisher test (ANOVA), $n$ - number of patients. 
Table 2

Correlation coefficient between psoriasis acceptance and selected variables

\begin{tabular}{ll}
\hline Variable & $\rho$ \\
\hline $\begin{array}{l}\text { Perceived support: } \\
\text { emotional }\end{array}$ & $.31^{* *}$ \\
$\quad$ instrumental & $.37^{* *}$ \\
Received support: & $.36^{* *}$ \\
$\quad$ emotional & $.17^{*}$ \\
$\quad$ instrumental & $.35^{* *}$ \\
$\quad$ informational & $.31^{* *}(\tau)$ \\
Support satisfaction & $-.29^{* *}$ \\
Lowered threshold & $-.24^{* *}$ \\
Heightened threshold & $-.34^{* *}$ \\
Interpretation & $-.33^{* *}$ \\
Regulation & $-.53^{* *}$ \\
Appearance satisfaction & $-.22^{* *}$ \\
Fitness satisfaction & $-.41^{* *}$ \\
Acceptance of biological sex &
\end{tabular}

Note. $\rho$ - Spearman coefficient, tau Kendall coefficient, ${ }^{* *} p<.01,{ }^{*} p<.05$.

tal, informational and emotional) as well as general beliefs about being accepted and comforted by others (emotional dimension), and their ability to provide help (instrumental support), contribute to disease acceptance. People who are satisfied with the support they receive cope with psoriasis more efficiently.

Acceptance of psoriasis is related to all aspects of body experience and body image. It means that patients who do not accept psoriasis experience both increased and decreased sensitivity to external stimuli (e.g. pain, touch, odours). Also, they have difficulty with understanding and coping with various emotions and body states, e.g. hunger or sexual arousal. Our results revealed a strong relationship between disease acceptance and appearance satisfaction and acceptance of biological sex, meaning that patients who do not accept psoriasis are also dissatisfied with their appearance and have negative emotions towards their sex attributes. They also perceive their fitness as impaired, with poor coordination and dislike of sports. Table 3 presents the results of multiple linear regression by the step method which was performed to identify predictors of psoriasis acceptance. Considering the fact that the variables related to body experience were highly intercorrelated, an aggregate variable was included - body experience. The same operation was applied to social support variables - the aggregated variable was social support. The investigated predictors included economic status, body experience, social support, appearance satisfaction, fitness satisfaction, and acceptance of biological sex. Appearance satisfaction, acceptance of biological sex, and social support proved to be the best predictors, explaining $33 \%$ of the variance of disease acceptance. Introduction remaining variables did not result in any significant increase of variance.

\section{DISCUSSION}

In our study, patient age, disease duration, and age at onset were comparable to results presented by Fuere, Adjadj, and Pawin (2005), in a large international survey, indicating that the studied populations can be considered as representative.

The first part of our study attempted to determine the relationship between sociodemographic variables and disease acceptance. Sex, relationship status, age, and education turned out to not contribute to disease acceptance, which is consistent with the results of Zalewska and her colleagues (2007). Only one sociodemographic factor, i.e. financial situation, played an important role in disease acceptance. In our study, patients were asked to subjectively assess their economic situation ("good", "average", "poor"), which could represent their general attitude toward the world and themselves (the optimism-pessimism dimension), rather than their actual income. Also, it could not be ruled out that financial resources determine the process of coping with the illness, allowing for better medical and cosmetic skincare.

In light of the previous studies, we did not expect medical variables such as PASI, disease duration, age at onset, and the presence of remissions to be related to disease acceptance. These results prove the limita-

Table 3

Results of regression analysis for the predictors of psoriasis acceptance

\begin{tabular}{lcccrc}
\hline & $B$ & Standard error & $\beta$ & $t$ & $p$ \\
\hline Constant value & 4.23 & 0.69 & & 6.06 & .001 \\
Appearance satisfaction & -0.40 & 0.09 & -.35 & -4.06 & .001 \\
Acceptance of biological sex & -0.59 & 0.19 & -.26 & -3.17 & .001 \\
Social support & 0.34 & 0.15 & -.20 & -2.29 & .024 \\
\hline
\end{tabular}

Note. Adj. $R^{2}=.33, F(7,101)=18.93, p<.001$. 
tions of the bio-medical model in explaining the process of coping with an illness, as postulated by Fortune, Richards, Griffiths, and Main (2002). Patients perceive and process the objective changes caused by the disease in an active manner. It means that cognitive evaluation of an illness in terms of a threat vs. a challenge is caused by objective severity of illness to a lesser degree than subjective meaning, which depends on psychological disposition.

All of the investigated aspects of social support significantly contributed to the ability to lead a satisfactory life despite psoriasis. Adaptation to psoriasis depended on the conviction about the presence of people who offered concrete assistance (instrumental support) and emotional support. As for support from a close friend or relative, emotional and informational support proved to be the most essential for disease acceptance, with instrumental support as the least important. Presence of a close person who offers emotional support and advice in dealing with everyday problems (informational support) is the key element of adaptation to psoriasis. Our findings demonstrate the buffering effect of support against negative consequences of a chronic disease, which is consistent with reports of other authors (Schiøtz, Bøgelund, Almdal, Jansen, \& Willaing, 2012; Janowski et al., 2012). Psoriasis patients, due to the nature of skin lesions, have to face social stigma, which leads to accumulation of negative perception, beliefs and emotions, e.g. shame or fear of rejection (Vardy et al., 2002). Bewley, Burrage, Ersser, Hansen, and Ward (2014) found that approximately half of psoriasis patients fear being perceived as dirty and unkempt, with infectious lesions. In light of these data, the importance of having people whose behaviour proves acceptance and involvement in the process of coping with disease seems understandable.

To the best of our knowledge, our study is the first to include the multi-dimensional body image and body experience model in a study on psoriasis patients. A study by Khoury et al. (2012) revealed negative body image in psoriasis patients, leading to hiding behind clothing and reduced physical activity. However, due to the small sample size (8 subjects), their results should be treated with caution. In turn, Leichtman and colleagues (1981) applied projective methodology, while comparing patients with mild and severe psoriasis, and managed to explain some of the differences in sexuality in the context of anxiety. Moreover, Wojtyna, Łakuta, Marcinkiewicz, Bergier-Czop, and Brzezińska-Wcisło (2017) found that negative beliefs about appearance are an important risk factor for depression in psoriasis patients. Notably, none of the studies examined the relationship between adaptation to the disease and body image. Our study demonstrated that disease acceptance is correlated with all of the aspects of body image and body experience. The strongest correlations were found for two body image aspects, i.e. appearance satisfaction and acceptance of biological sex, although fitness satisfaction also played a part in the coping process. Earlier studies proved that psoriasis patients implement various strategies to avoid exposing their body, e.g. by avoiding activities which require them to uncover their body in public places (swimming pool, gym; Khoury et al., 2012). These results allowed us to hypothesize that people who accept their appearance, despite the imperfections, are able to lead a satisfying life, which was confirmed by our findings. It seems necessary to emphasize a strong connection between acceptance of one's biological sex and coping with psoriasis. Our results demonstrated that satisfaction with one's sexuality and deriving pleasure from being a man or a woman constitutes a promoting factor for coping with psoriasis. Furthermore, it turned out that acceptance of disease is related to fitness satisfaction. One possible explanation for this finding is that participation in sports activity positively influences patient well-being and general self-esteem (Zade, Mahmoodi, \& Hashemi, 2015), reinforcing the belief in leading a satisfying life, despite skin lesions. However, it is also possible that people who are free from physical restraint resulting from the disease may take part in numerous sports activities, which affects the perception and evaluation of their physical fitness.

All of the investigated body experience aspects were related to disease acceptance. Our findings revealed that disorders expressed as increased and decreased sensitivity to external stimuli, and difficulty with identifying and dealing with emotions or physiological needs, negatively contribute to coping with disease. Based on our results, it seems safe to conclude that the ability of undisturbed processing of sensations, physiological needs, and emotions constitutes a promoting factor for overcoming disease-related limitations. Notably, the accurate perception of stimuli, emotions and physiological needs is acquired during development, but such circumstances as longterm disease may disrupt that process. Interestingly, disease duration was linked with lower threshold of sensations ( $\rho=.17, p=.042)$, emotion and need regulation $(\rho=.22, p=.011)$, and fitness satisfaction $(\rho=.18, p=.034)$. In other words, longer disease duration was positively correlated with various kinds of oversensitivity, difficulty with cause identification and coping with emotions and physiological needs, as well as low self-assessed fitness. We believe that this finding is of the utmost importance. Firstly, it demonstrates that chronic psoriasis may be considered to be a risk factor for disturbances within the body image and body experience. Secondly, it implies that although disease severity does not directly influence the process of adjusting to disease, it influences body image and body experience, thus affecting the dependent variable.
Acceptance of psoriasis, body image and social support 
The importance of body image and social support was confirmed in the results of regression analysis, which aimed to identify the main predictors of the dependent variable: appearance satisfaction, acceptance of biological sex and social support.

\section{CONCLUSIONS}

Psychological adjustment to psoriasis is relatively Olga Sakson-Obada, Mariola Pawlaczyk, Katarzyna Gerke, Zygmunt Adamski independent of the medical parameters of the disease, which demonstrates the limitations of the biomedical model in explaining the process of coping with the disease. Satisfaction with one's appearance and sexuality - two aspects of body image which are independent of the severity of psoriasis - together with social support, are the key factors that contribute to leading a satisfactory life despite the disease. Moreover, disturbances in body experience (stimuli, emotions, and physiological needs) seem to be risk factors for perceiving psoriasis as a heavy burden. The obtained results help to understand why disappointment with treatment and non-adherence to therapy are observed in some cases, even when the severity of psoriasis is decreasing. Persistent body dissatisfaction and lack of a close relationship may suggest that additional psychological support, focusing on body image and body experience, needs to be addressed.

\section{RefERENCES}

Adamska, M., \& Miniszewska, J. (2016). Determinants of acceptance of an illness in the case of patients suffering from psoriasis treated in the hospital and outpatient clinic settings. Health Psychology Report, 4, 54-64.

Basińska, M. A., \& Kasprzak, A. (2012). Związek między strategiami radzenia sobie ze stresem a akceptacją choroby w grupie osób chorych na łuszczyce [The relationship between strategies of coping with stress and acceptance of illness among patients with psoriasis]. Przeglad Dermatologiczny, 99, 692-700.

Bewley, A., Burrage, D. M., Ersser, S. J., Hansen, M., \& Ward, C. (2014). Identifying individual psychosocial and adherence support needs in patients with psoriasis: a multinational two-stage qualitative and quantitative study. Journal of the European Academy of Dermatology and Venereology, 28, 763-770.

Blashill, A. J., \& Wilhelm, S. (2014). Body image distortions, weight, and depression in adolescent boys: longitudinal trajectories into adulthood. Psychology of Men \& Masculinity, 15, 445-451.

Cash, T. F., \& Deagle, E. A. (1997). The nature and extent of body-image disturbances in anorexia nervosa and bulimia nervosa: A meta-analysis. International Journal of Eating Disorders, 2, 107-126.

Felton, B. J., Revenson, T. A., \& Hinrichsen, G. A. (1984). Stress and coping in the explanation of psychological adjustment among chronically ill adults. Western Journal of Nursing Research Western, 14, 211-224.

Fortune, D. G., Richards, H. L., Griffiths, C. E., \& Main, C. J. (2002). Psychological stress, distress and disability in patients with psoriasis: consensus and variation in the contribution of illness perceptions, coping and alexithymia. British Journal of Clinical Psychology, 41, 157-174.

Fuere, S., Adjadj, L., \& Pawin, H. (2005). How patients experience psoriasis: results from European survey. Journal of the European Academy of Dermatology and Venereology, 19, 2-6.

Gupta, M. A., \& Gupta, A. K. (1995). The Psoriasis Life Stress Inventory: a preliminary index of psoriasis - related stress. Acta Dermato-Venereologica, $75,240-243$.

Gupta, M. A., Gupta, A. K., \& Haberman, H. F. (1987). Psoriasis and psychiatry: an update. General Hospital Psychiatry, 9, 157-166.

Hayes, J., \& Ko, J. (2010). Psoriasis: depression, anxiety, smoking and drinking habits. Dermatology and Therapy, 23, 174-188.

Janowski, K., Steuden, S., Pietrzak, A., Krasowska, D., Kaczmarek, Ł., Gradus, I., \& Chodorowska, G. (2012). Social support and adaptation to disease in men and women with psoriasis. Archives of Dermatological Research, 304, 421-432.

Juczyński, Z. (2009). Narzędzia pomiaru w promocji i psychologii zdrowia [Measurment tools in promotion and psychology of health]. Warszawa: Pracownia Testów Psychologicznych Polskiego Towarzystwa Psychologicznego.

Khoury, L. R., Danielsen, P., \& Skiveren, J. (2012). Body image altered by psoriasis. A study based on individual interviews and a model for body image. Journal of Dermatological Treatment, 25, 2-7.

Kubiak, A., \& Sakson-Obada, O. (2016). Repetitive self-injury and the body self. Psychiatria Polska, 50, 43-54.

Kurd, S. K., \& Gelfand, J. M. (2009). The prevalence of previously diagnosed and undiagnosed psoriasis in US adults: results from NHANES 2003-2004. Journal of the American Academy of Dermatology, 60, 218-224.

Leichtman, S. R., Burnett, J. W., \& Robinson, H. M. (1981). Body image concerns of psoriasis patients as reflected in human figure drawings. Journal of Personality Assessment, 45, 478-484.

Leventhal, H., Benyamini, Y., Brownlee, S., Diefenbach, M., Leventhal, E. A., Patrick-Miller, L., \& Robitaille, C. (1997). Illness representation: Theoretical foundation. In K. Petrie \& J. A. Weinman (eds.), Perception of Health and Illness (pp. 19-46). London: Harwood Academic Publisher. 
Łuszczyńska, A., Kowalska, M., Mazurkiewicz, M. \& Schwarzer, R. (2006). Berlińskie Skale Wsparcia Społecznego (BSSS). Wyniki wstępnych badań nad adaptacją skal i ich własnościami psychometrycznymi [Berlin Social Support Scales (BSSS): Polish version of BSSS and preliminary results on its psychometric properties]. Studia Psychologiczne, 44, 17-27.

Molina-Leyva, A., Jiménez-Moleón, J. J., Naranjo-Sintes, R., \& Ruiz-Carrascosa, J. C. (2015). Sexual dysfunction in psoriasis: a systematic review. Journal of the European Academy of Dermatology and Venereology, 29, 649-655.

Richards, H. L., Fortune, D. G., Griffith, E. M., \& Main, C. J. (2001). The contribution of perception of stigmatization to disability in patients with psoriasis. Journal of Psychiatric Research, 50, 11-15.

Sakson-Obada, O. (2009). Pamięć ciata. Ja cielesne w przywiqzaniu i traumie [Memory of the body. Body Self in trauma and attachment]. Warszawa: Difin.

Sakson-Obada, O., \& Wycisk, J. (2015). The body self and the frequency, intensity and acceptance of menopausal symptoms. Przeglad Menopauzalny, 14, 82-89.

Schiøtz, M. L., Bøgelund, M., Almdal, T., Jansen, B. B., \& Willaing, I. (2012). Social support and self-management behaviour among patients with Type 2 diabetes. Diabetic Medicine, 29, 654-661.

Schmitt, J., \& Wozel, G. (2005). The Psoriasis Area and Severity Index is the adequate criterion to define severity in chronic plaque-type psoriasis. Dermatology, 210, 194-199.

Schulz, U., \& Schwarzer, R. (2003). Soziale Unterstützung bei der Krankheitsbewältigung. Die Berliner Social Support Skalen (BSSS) [Social support in coping with illness: The Berlin Social Support Scales (BSSS)]. Diagnostica, 49, 73-82.

Teo, I., Novy, D. M., Chang, D. W., Cox, M. G., \& Fingeret, M. C. (2015). Examining pain, body image, and depressive symptoms in patients with lymphedema secondary to breast cancer. Psychooncology, 24, 1377-1383.

Vardy, D., Besser, A., Amir, M., Biton, A., \& Buskila D. (2002). Experiences of stigmatization play a role in mediating the impact of disease severity on quality of life in psoriasis patients. British Journal of Dermatology, 147, 736-742.

Wojtyna, E., Łakuta, P., Marcinkiewicz, K., BergierCzop, B., \& Brzezińska-Wcisło, L. (2017). Gender, body image and social support: Biopsychosocial determinants of depression among patients with psoriasis. Acta Dermato-Venereologica, 96, 91-97.

Zade, T. T., Mahmoodi, M., \& Hashemi, L. (2015). Study of the effectiveness of exercise on the self-esteem, happiness, and quality of life. Trends in Life Science, 4, 123-129.
Zalewska, A., Miniszewska, J., Chodkiewicz, J., \& Narbutt, J. (2007). Acceptance of chronic illness in psoriasis vulgaris patients. Journal of the European Academy of Dermatology and Venereology, 21, 235-242.
Acceptance of psoriasis, body image and social support 